
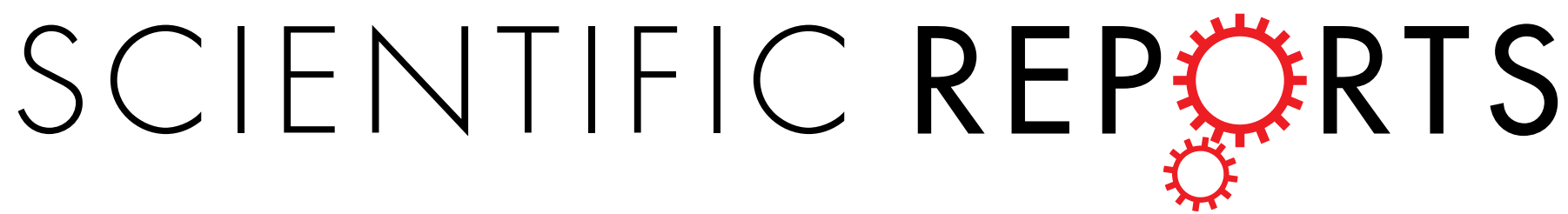

\title{
Ultrahard stitching of nanotwinned diamond and cubic boron nitride in $\mathrm{C}_{2}$-BN composite
}

Received: 10 May 2016

Accepted: 04 July 2016

Published: 27 July 2016

\section{Xiaobing Liu ${ }^{1}$, Xin Chen ${ }^{1}$, Hong-An Ma², Xiaopeng Jia ${ }^{2}$, Jinsong Wu${ }^{3}$, Tony $\mathrm{Yu}^{4}$, Yanbin Wang ${ }^{4}$, Jiangang Guo ${ }^{5}$, Sylvain Petitgirard ${ }^{6}$, Craig R. Bina ${ }^{1} \&$ Steven D. Jacobsen ${ }^{1}$}

Materials combining the hardness and strength of diamond with the higher thermal stability of cubic boron nitride ( $C B N$ ) have broad potential value in science and engineering. Reacting nanodiamond with $C B N$ at moderate pressures and high temperatures provides a pathway to such materials. Here we report the fabrication of $C_{x}-B N$ nanocomposites, measuring up to $10 \mathrm{~mm}$ in longest dimension, by reacting nanodiamond with pre-synthesized $c B N$ in a large-volume press. The nanocomposites consist of randomly-oriented diamond and $c B N$ domains stitched together by $s p^{3}$-hybridized C-B and $\mathrm{C}-\mathrm{N}$ bonds, leading to $p$-type semiconductivity. Dislocations near the sutures accommodate lattice mismatch between diamond and $c B N$. Nanotwinning within both diamond and $c B N$ domains further contributes to a bulk hardness $\sim 50 \%$ higher than sintered $c B N$. The nanocomposite of $C_{2}-B N$ exhibits p-type semiconductivity with low activation energy and high thermal stability, making it a functional, ultrahard substance.

Superhard and ultrahard materials, presently defined as having Vickers hardness $\left(H_{V}\right)$ greater than 40 and $80 \mathrm{GPa}$, respectively, are sought after for their potential use as extreme abrasives and other applications in high-pressure science and technology ${ }^{1-4}$. Diamond is generally considered the hardest known substance, but due to graphitization in air at 800-900 K and reactivity with transition metals at high temperature, diamond has limited application in certain grinding environments. Cubic boron nitride $(c \mathrm{BN})$, a diamond-structured compound, is widely used as an abrasive with much higher thermal stability than diamond $(\sim 1473 \mathrm{~K})$ and low reactivity with steel, but the Vickers hardness of $c \mathrm{BN}(40-60 \mathrm{GPa})^{5,6}$ is only about half that of diamond. Because of their similar ionic radii, $\mathrm{B}, \mathrm{C}$, and $\mathrm{N}$ may form diamond-like compounds in solid solution that are expected to be ultrahard with higher thermal and chemical stability than diamond ${ }^{7-12}$. Based on theoretical predictions, experimental studies have attempted to synthesize a number of superhard $\mathrm{B}-\mathrm{C}-\mathrm{N}$ materials including diamond-like $\mathrm{BC}_{2} \mathrm{~N}^{13}, \mathrm{BC}_{4} \mathrm{~N}^{10}$, $\mathrm{BC}_{3}{ }^{14}$ and $\mathrm{BC}_{5}{ }^{15,16}$. However, solid-solution $\mathrm{B}-\mathrm{C}-\mathrm{N}$ phases are generally considered metastable because syntheses usually lead to segregated carbon and boron compounds ${ }^{17}$. The extremely high pressures $(20-25 \mathrm{GPa})$ and temperatures $(2000-2500 \mathrm{~K})$ of many B-C-N syntheses ultimately limit production potentials and sample size ${ }^{7,15,17}$.

Recently, it was discovered that nanotwinned (nt) diamond ${ }^{3}$ and $n t-c \mathrm{BN}^{2,18}$ possess ultrahigh hardness and toughness, mitigating the so-called reverse Hall-Petch effect by shear strengthening from compressive forces across nanospaced twin boundaries ${ }^{18}$. Combining nt-diamond and nt- $c \mathrm{BN}$ to create an ultrahard nanocomposite would potentially lead to a material with optimized properties of each. Reacting diamond and $c \mathrm{BN}$ at high pressure and high temperature (HPHT) has been the typical route to synthesizing composites of diamond and cubic boron nitride $\left(\mathrm{C}_{x}-\mathrm{BN}\right)^{19-23}$, where $x$ is the proportion of diamond relative to $c \mathrm{BN}$. The conditions and mechanisms of stitching diamond and $c \mathrm{BN}$ together remains the primary challenge. Recently, an epitaxial $c \mathrm{BN} /$ diamond heterojunction was produced by growing single-crystal $c \mathrm{BN}$ on diamond seed crystals using a temperature gradient $\operatorname{method}^{24}$. A network of continuous stacking faults, arranged by hexagonal dislocation loops on the $\{111\}$ heterointerface was found to accommodate the $c \mathrm{BN} /$ diamond lattice mismatch $(\sim 1.4 \AA)^{24}$. In this study, we fabricated

${ }^{1}$ Department of Earth and Planetary Sciences, Northwestern University, Evanston, Illinois 60208, USA. ${ }^{2}$ State Key Laboratory of Superhard Materials, Jilin University, Changchun, Jilin 130012, China. ${ }^{3}$ Northwestern University Atomic and Nanoscale Characterization Experimental (NUANCE) center, Northwestern University, Evanston, Illinois 60208, USA. ${ }^{4}$ Center for Advanced Radiation Sources, University of Chicago, Chicago, Illinois 60439, USA. ${ }^{5}$ Department of Physics \& Astronomy, Rice University, Houston, Texas 77005-1827, USA. ${ }^{6}$ Bayerisches Geoinstitut, University of Bayreuth, Bayreuth 95444, Germany. Correspondence and requests for materials should be addressed to X.L. (email: xiaobing@earth.northwestern.edu) 


\begin{tabular}{|c|c|c|c|c|c|c|c|}
\hline Run & Sample & $P(G P a)$ & $\mathbf{T}(\mathbf{K})$ & $p / n$ & $\begin{array}{c}\text { Resistivity } \\
(\Omega \mathrm{cm})\end{array}$ & $\begin{array}{l}\text { Hall mobility } \\
\left(\mathrm{cm}^{2} / \mathrm{VS}\right)\end{array}$ & $\begin{array}{l}\text { Carrier concentration } \\
\left(\mathrm{cm}^{-3}\right)\end{array}$ \\
\hline S-1 & Sintered-BN & 7.5 & 2273 & 1 & I & I & I \\
\hline S-2 & $\mathrm{C}_{2}-\mathrm{BN}$ & 7.5 & 2273 & $p$ & 1.652 & 37.55 & $1.006 \mathrm{E} 17$ \\
\hline S-3 & $\mathrm{C}_{4}-\mathrm{BN}$ & 7.5 & 2273 & $p$ & 0.162 & 2.67 & $1.439 \mathrm{E} 19$ \\
\hline S-4 & $\mathrm{C}_{6}-\mathrm{BN}$ & 7.5 & 2273 & $p$ & 0.571 & 364.69 & $2.999 \mathrm{E} 16$ \\
\hline S-5 & $\mathrm{C}_{8}-\mathrm{BN}$ & 7.5 & 2273 & $n$ & 0.055 & 46.62 & $2.426 \mathrm{E} 18$ \\
\hline S-6 & Sintered-C & 7.5 & 2273 & $n$ & 0.014 & 15.68 & $2.749 \mathrm{E} 19$ \\
\hline S-7 & Single-crystal diamond & $5-5.5$ & 1500 & I & I & I & I \\
\hline S-8 & Single-crystal $c B N$ & 4.8 & 1400 & I & I & I & I \\
\hline \multicolumn{8}{|c|}{ Microcrystalline samples } \\
\hline S-9 & $\mathrm{C}_{2}-\mathrm{BN}$ (microcrystalline) & 7.5 & 2273 & $p$ & 6.38 & 6.55 & $1.490 \mathrm{E} 16$ \\
\hline S-10 & $\mathrm{C}_{2}-\mathrm{BN}$ (microcrystalline) & 7.5 & 1800 & $p$ & 1064 & 162 & $3.624 \mathrm{E} 14$ \\
\hline
\end{tabular}

Table 1. Synthesis conditions and electrical properties of nanopolycrystalline $\mathrm{C}_{x}$-BN composites. Temperature was held constant for two hours. The $\mathrm{C}_{x}$ - $\mathrm{BN}$ composites consist of sintered nanodiamond $(50 \mathrm{~nm})$ and $c \mathrm{BN}(250 \mathrm{~nm})$ with varying ratios $(x)$ of diamond to $c \mathrm{BN}$. For comparison, microcrystalline $\mathrm{C}_{2}-\mathrm{BN}$ composites from two different synthesis temperatures demonstrate the decrease in resistivity with increasing temperature between 1800 and $2273 \mathrm{~K}$.
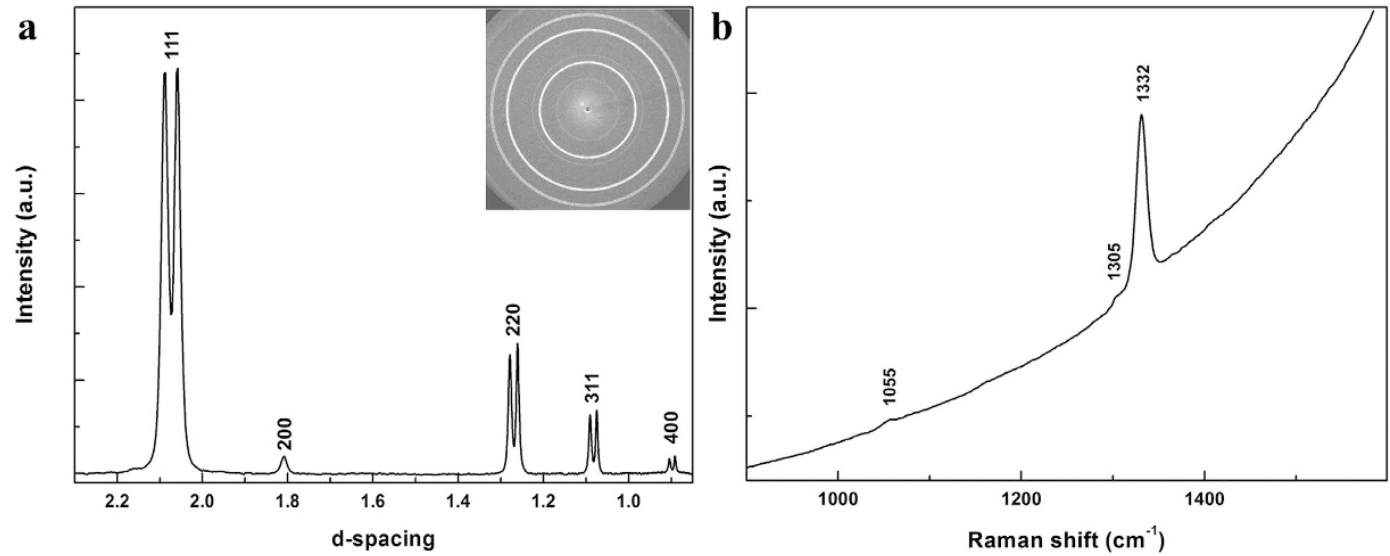

Figure 1. Characterization of $\mathrm{C}_{2}-\mathrm{BN}$ synthesized at $7.5 \mathrm{GPa}$ and $2273 \mathrm{~K}$. (a) XRD and (b) Raman spectra indicate two components, diamond and $c \mathrm{BN}$. Rings in the CCD image (top-right inset in 1a) show the polycrystalline texture of well-sintered $\mathrm{C}_{2}$ - $\mathrm{BN}$ composite.

highly uniform $\mathrm{C}_{x}$ - $\mathrm{BN}(x=2,4,6,8)$ nanocomposites at $7.5 \mathrm{GPa}$ and $2273 \mathrm{~K}$, which consist of randomly oriented, $\sim 50 \mathrm{~nm}$ domains of diamond and $c B N(\sim 250 \mathrm{~nm})$. The bulk samples, measuring up to $10-\mathrm{mm}$ diameter by $5-\mathrm{mm}$ in height, combine several novel features from recent syntheses in the diamond- $c \mathrm{BN}$ system ${ }^{2,3,18,24}$; in particular, the new $\mathrm{C}_{2}-\mathrm{BN}$ composite possesses nanotwinning in both diamond and $c \mathrm{BN}$ domains, which are stitched by $s p^{3}$-hybridized C-B and C-N bonds along randomly-oriented interfaces. Near the sutures, dislocations accommodate the lattice mismatch between diamond and $c \mathrm{BN}$ and, as recently predicted ${ }^{24}$, the $\mathrm{C}_{2}-\mathrm{BN}$ nanocomposite is a $p$-type semiconductor with low activation energy. Among the suite of new nanocomposites, $\mathrm{C}_{2}-\mathrm{BN}$ is the hardest, with $H v=85(2) \mathrm{GPa}$, placing it in the ultrahard class of materials.

We control the stoichiometry in $\mathrm{C}_{x}-\mathrm{BN}$, by varying the proportions of starting powders of diamond (average grain size $50 \mathrm{~nm}$ ) and $c \mathrm{BN}$ (average grain size $250 \mathrm{~nm}$ ). Synthesis was conducted at $7.5 \mathrm{GPa}$ while holding constant temperature of $2273 \mathrm{~K}$ for two hours (Table 1). The components of $\mathrm{C}_{2}$ - $\mathrm{BN}$ remain diamond-structured; however, the recovered $\mathrm{C}_{x}-\mathrm{BN}$ composites with $\mathrm{C}_{4}-\mathrm{BN}, \mathrm{C}_{6}-\mathrm{BN}$, and $\mathrm{C}_{8}-\mathrm{BN}$ contained diamond and $c \mathrm{BN}$ together with appearance of graphitic phase (Fig. S1). The presence of minor amounts of graphite decreases with increasing ratio of $c \mathrm{BN}$ added to the starting material, indicating that $c \mathrm{BN}$ plays a role as catalyst in stitching diamond and $c \mathrm{BN}$ domains while protecting the diamond from graphitization at the high temperatures of synthesis $(2273 \mathrm{~K})$. Since the aim of this study is to synthesize and characterize nanopolycrystalline $\mathrm{C}_{x}$ - $\mathrm{BN}$ composite free of graphite, here we focus on the physical properties of $\mathrm{C}_{2}-\mathrm{BN}$, which was the only sample not exhibiting the presence of graphite.

Figure la shows a representative X-ray diffraction (XRD) pattern of the recovered $\mathrm{C}_{2}-\mathrm{BN}$ composite. With increasing synthesis temperature, the diffraction lines become broader and the peaks of diamond and $c \mathrm{BN}$ from the $2273 \mathrm{~K}$ synthesis have considerable overlap (Fig. S1). Raman spectra (Fig. 1b) of $\mathrm{C}_{2}-\mathrm{BN}_{\text {produced at }}$ $7.5 \mathrm{GPa}$ and $2273 \mathrm{~K}$ are dominated by one sharp Raman peak at $1332 \mathrm{~cm}^{-1}$ and two weak peaks at about 1055 and $1305 \mathrm{~cm}^{-1}$, corresponding to diamond and $c \mathrm{BN}$ longitudinal optical and transverse optical modes, respectively. 

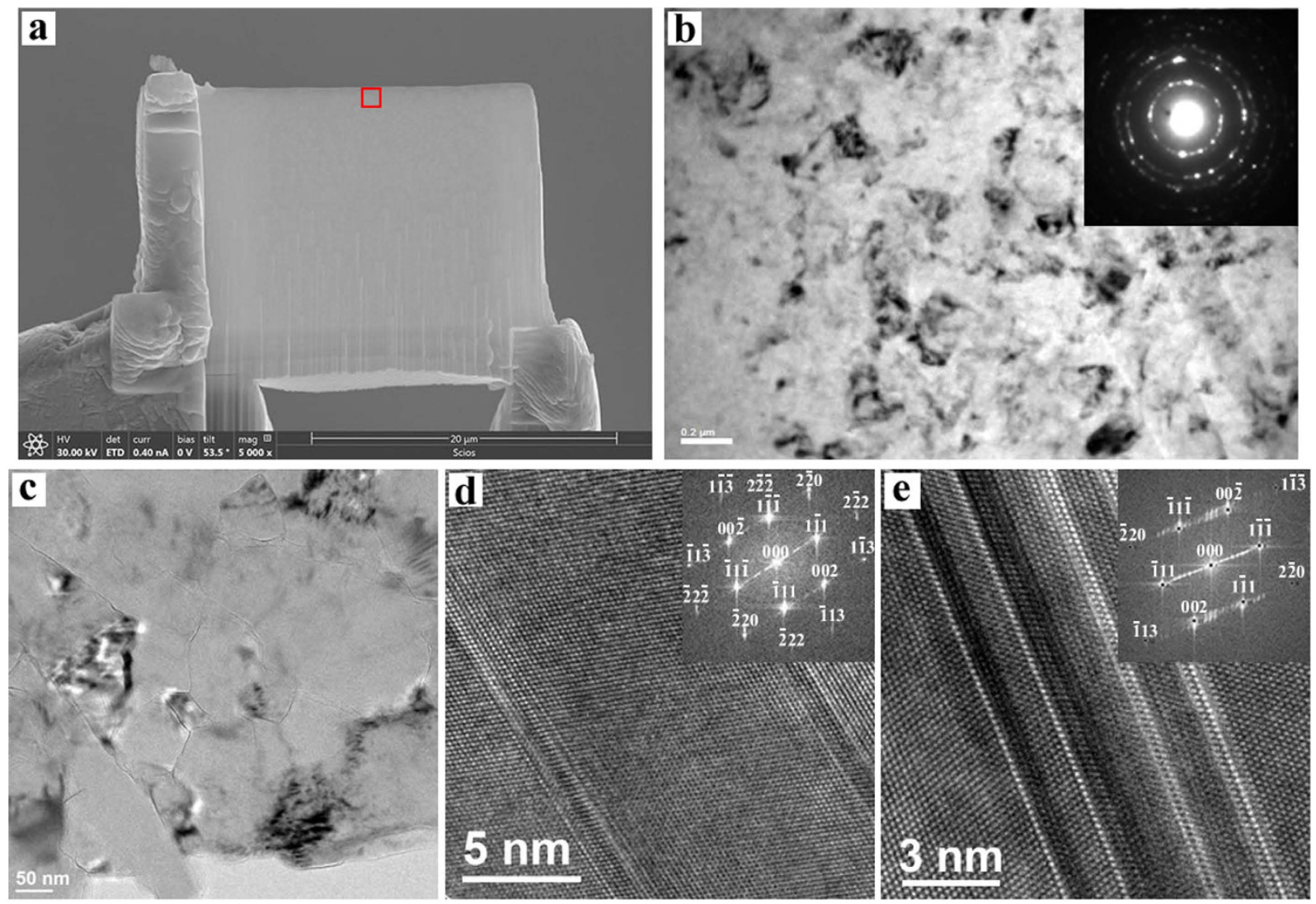

Figure 2. Microstructure of nanocomposite $\mathrm{C}_{2}$-BN. (a) TEM lamellae obtained from a $\mathrm{C}_{2}$-BN bulk sample before focused ion-beam (FIB) thinning. (b,c) TEM images of the area with the red box in (a). The inset of (b) shows a selected area diffraction (SAED) pattern (d and e) HRTEM images of the nanotwinned diamond and $c \mathrm{BN}$ domains. Insets show calculated FFT patterns of the two main domains.

The Fourier transform infrared (FTIR) spectrum (Fig. S2) shows two main peaks at 1065 and $1318 \mathrm{~cm}^{-1}$ together with one weak shoulder at $1208 \mathrm{~cm}^{-1}$, which correspond to stretching of the $s p^{3} \mathrm{~B}-\mathrm{N}$ bonds in $c \mathrm{BN}^{21,22}, \mathrm{C}-\mathrm{N}$ bonds within the sutures of diamond and $c \mathrm{BN}$ domains ${ }^{25}$ and $\mathrm{C}-\mathrm{C}$ bonds in diamond ${ }^{26}$, respectively. This characterization shows that the $\mathrm{C}_{2}-\mathrm{BN}$ samples consist of diamond and $c \mathrm{BN}$ domains, consistent with XRD data (Fig. 1a). The recovered samples from $7.5 \mathrm{GPa}$ and $1500-2273 \mathrm{~K}$ were black and opaque, while transparent samples were achieved by subsequent annealing at $15-18 \mathrm{GPa}$ and $2100 \mathrm{~K}$ (Fig. S3).

Scanning electron microscopy (SEM) confirms the $\mathrm{C}_{2}-\mathrm{BN}$ composite is uniform and well sintered (Fig. 2a). Thin foils of $\mathrm{C}_{2}$ - $\mathrm{BN}$ synthesized at $7.5 \mathrm{GPa}$ and $2273 \mathrm{~K}$ were prepared by focused-ion beam (FIB) techniques for transmission electron microscopy (TEM). Characteristic TEM and high-resolution TEM (HRTEM) images are shown in Fig. 2b-e. The TEM images in Fig. 2b,c show the absence of porosity in the $\mathrm{C}_{2}$ - $\mathrm{BN}$ sample, unlike many sintered diamond samples from which catalysts have been removed. The samples exhibit a nanopolycrystalline structure, consisting of hybridized, randomly distributed diamond and $c$ BN domains (Figs S4 and S5). Furthermore, HRTEM images reveal that nanotwinned structures have been produced during HPHT treatment (Fig. $2 \mathrm{~d}, \mathrm{e}$ ). These multiple twins in the diamond and $c \mathrm{BN}$ domains are $1.5-2 \mathrm{~nm}$ and $6-8 \mathrm{~nm}$ wide, respectively. HRTEM images in Fig. 3 show that the two main domains of diamond and $c$ BN have been stitched together by high-pressure sintering. The rigid lattice misfit between diamond and $c \mathrm{BN}$ domains is accommodated by the presence of partial dislocations and stacking faults at the interface between the two domains (Fig. S6) ${ }^{24}$. The sutures between diamond- $c$ BN domains are typically $1-2 \mathrm{~nm}$ thick. HRTEM images and selected area electron diffraction (SAED) patterns (Fig. $3 c$,d) from the diamond- $c \mathrm{BN}$ junctions reveal that $c \mathrm{BN}$ domains twin to conjoin the adjacent diamond. Stacking faults and dislocations are observed in $c \mathrm{BN}$ in close proximity to the interfaces (Fig. S6). Through this misfit accommodation mechanism ${ }^{24}$, strain between diamond and $c \mathrm{BN}$ domains is released, leading to stability of the $\mathrm{C}_{2}-\mathrm{BN}$ composite.

To determine the local bonding characteristics across the diamond- $c \mathrm{BN}$ sutures, we carried out inelastic $\mathrm{X}$-ray scattering (IXS; beam size $20 \mu \mathrm{m}$ ) and electron energy-loss spectroscopy (EELS; beam size $1 \mathrm{~nm}$ ) on the $\mathrm{C}_{2}-\mathrm{BN}$ sample. The IXS spectra in Fig. S7 show that all three elements, B, C and N, are $s p^{3}$ hybridized along the sutures. In contrast, pure diamond sintered under identical conditions ( $7.5 \mathrm{GPa}$ and $2273 \mathrm{~K}$ ) exhibits both $s p^{2}$ and $s p^{3}$ bonds (Fig. S8). This confirms that graphitization of sintered diamond can be effectively minimized or eliminated in $\mathrm{C}_{2}$ - $\mathrm{BN}$ by choosing the optimal synthesis conditions. EELS was conducted to analyze the interface between diamond and $c \mathrm{BN}$ from the selected area in the $\mathrm{C}_{2}-\mathrm{BN}$ sample from $2273 \mathrm{~K}$ (Fig. $4 \mathrm{a}$ ). Figure $4 \mathrm{~b}$ shows the EELS spectrum and all the three bonds corresponding to the characteristic $K$-shell ionization edges of $\mathrm{B}, \mathrm{C}$ and $\mathrm{N}$ in 

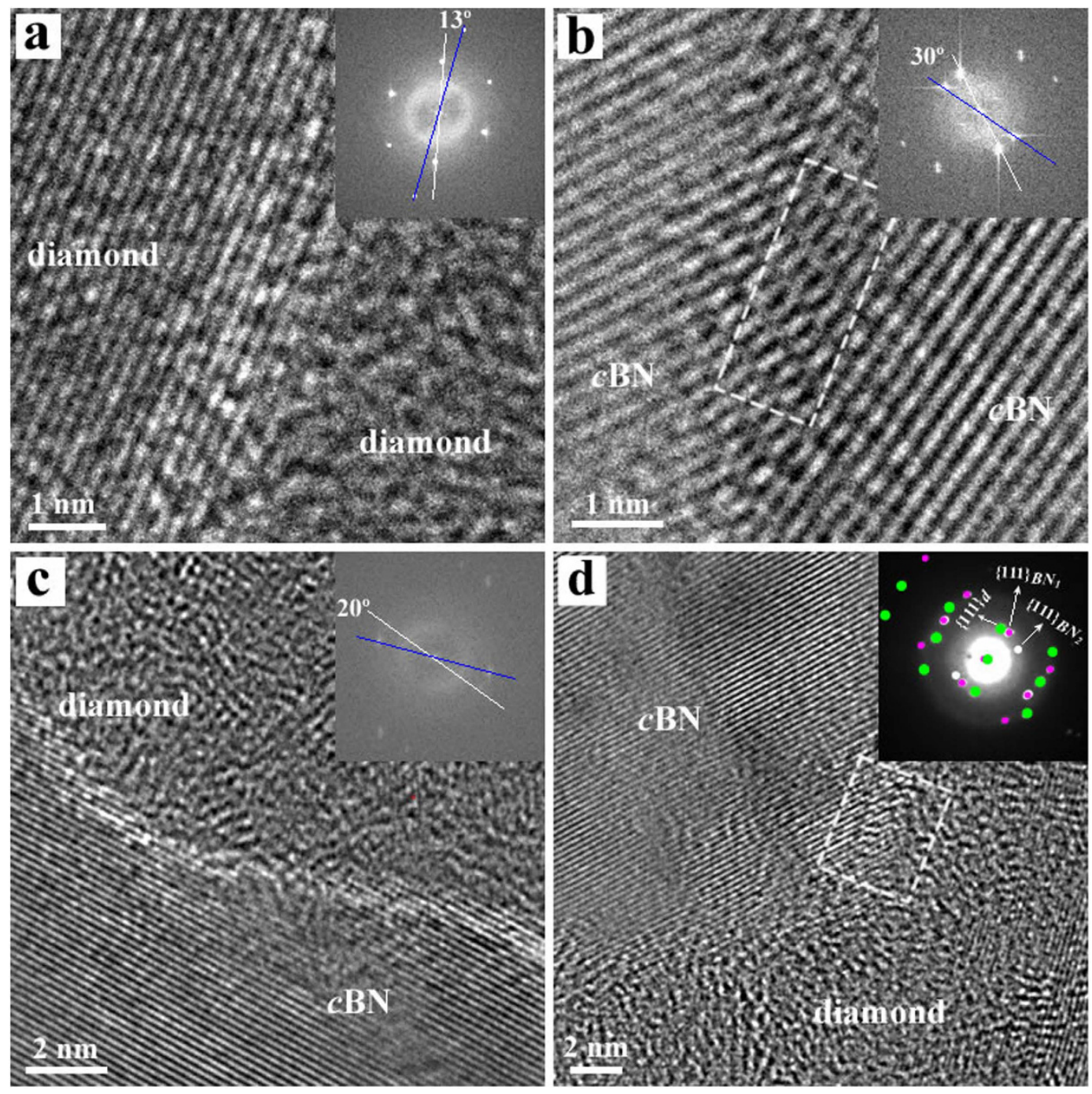

Figure 3. Ultrahard sutures in nanocomposite $\mathrm{C}_{2}$-BN. (a-c) HRTEM images at the junction between diamond and $c \mathrm{BN}$ domains. The FFT inset shows the rotation angles between adjacent diamond or $c \mathrm{BN}$ domains. (d) HRTEM and corresponding SAED pattern from a typical junction indicates that only nanotwinned diamond and $c \mathrm{BN}$ are present at the interface. Dislocations and stacking faults at the interface are found in the region marked by the white rectangle in (b) and (d).

the diamond- $c \mathrm{BN}$ interface. These EELS edge structures prove that bonding within the sutures are primarily $s p^{3}$-hybridized B-C-N bonds together with small amount of $s p^{2} \mathrm{C}$-B bonds.

$\mathrm{X}$-ray photoelectron spectroscopy (XPS) was performed to study the stoichiometry of the hybridized diamond- $c B N$ junctions. Figures $4 c-e$ show XPS spectra of B, N and C, respectively. The shape and position of the spectra for all three elements are different from previous studies on pure diamond ${ }^{27}, c \mathrm{BN}^{28}$, and $\mathrm{B}-\mathrm{C}-\mathrm{N}$ compounds ${ }^{29,30}$. The $\mathrm{C} 1 s$ peak is located at $285.2 \mathrm{eV}$ (Fig. $4 \mathrm{c}$ ), which is similar to the value of C $1 s$ in $s p^{3} \mathrm{C}-\mathrm{C}$ bonds observed in diamond ${ }^{31}$. The full width at half-maximum (FWHM) is about $2.3 \mathrm{eV}$, suggesting different valence states of carbon are present. Two smaller peaks at higher $(285.9 \mathrm{eV})$ and lower $(284.5 \mathrm{eV})$ binding energy are due to $\mathrm{C} 1 s$ in $s p^{3} \mathrm{C}-\mathrm{N}$ and $\mathrm{C}-\mathrm{B}$ bonds, respectively ${ }^{32}$. In addition, a higher binding energy at $289.0 \mathrm{eV}$ is observed from the contribution of $\mathrm{C} 1 s$ in $\mathrm{C}-\mathrm{O}$ bonds ${ }^{29,33}$. The main peak of the $\mathrm{B} 1 s$ spectrum is located at $190.7 \mathrm{eV}$, very close to that of $\mathrm{B} 1 s(191.0 \mathrm{eV})$ in pure $c \mathrm{BN}^{28,29}$, suggesting the main bonding configuration in the $\mathrm{C}_{2}-\mathrm{BN}$ composite produced at $7.5 \mathrm{GPa}$ and $2273 \mathrm{~K}$ is similar to that of $c \mathrm{BN}$, where one $\mathrm{N}$ atom is surrounded by four $\mathrm{B}$ atoms. However, a small shoulder at lower binding energy implies a contribution of B and C, because of the lower electronegativity of $\mathrm{C}$ atoms than $\mathrm{N}^{34}$. A higher binding energy at $192.4 \mathrm{eV}$ implies a contribution from the configuration of $\mathrm{B} 1 s$ in $\mathrm{B}-\mathrm{O}$ bond ${ }^{35}$. The $\mathrm{N} 1 s$ binding energy is located at $398.4 \mathrm{eV}$ (Fig. $4 \mathrm{e}$ ), similar to the position of $\mathrm{N} 1 s$ in $c \mathrm{BN}^{28,29}$. However, two small shoulders are observed at higher binding energy of 400.3 and $402.1 \mathrm{eV}$, which are due to $\mathrm{N} 1 s$ in $\mathrm{C}-\mathrm{N}$ and $\mathrm{C}-\mathrm{O}$, respectively ${ }^{29,30}$. All the $\mathrm{C} 1 s, \mathrm{~B} 1 s$ and $\mathrm{N} 1 s$ spectra indicate that the main configuration for $\mathrm{C}, \mathrm{B}$ and $\mathrm{N}$ atoms is $s p^{3} \mathrm{~B}-\mathrm{N}$ bonding, together with a contribution from the bonding configuration in the boundary region between diamond and $c \mathrm{BN}$ domains. In addition to $s p^{3}$-hybridized $\mathrm{C}-\mathrm{N}$ and $\mathrm{C}-\mathrm{B}$ bonds produced during HPHT reaction, some $\mathrm{C}-\mathrm{O}, \mathrm{B}-\mathrm{O}$, and $\mathrm{N}-\mathrm{O}$ bonds remain from the starting materials exposed to air. 

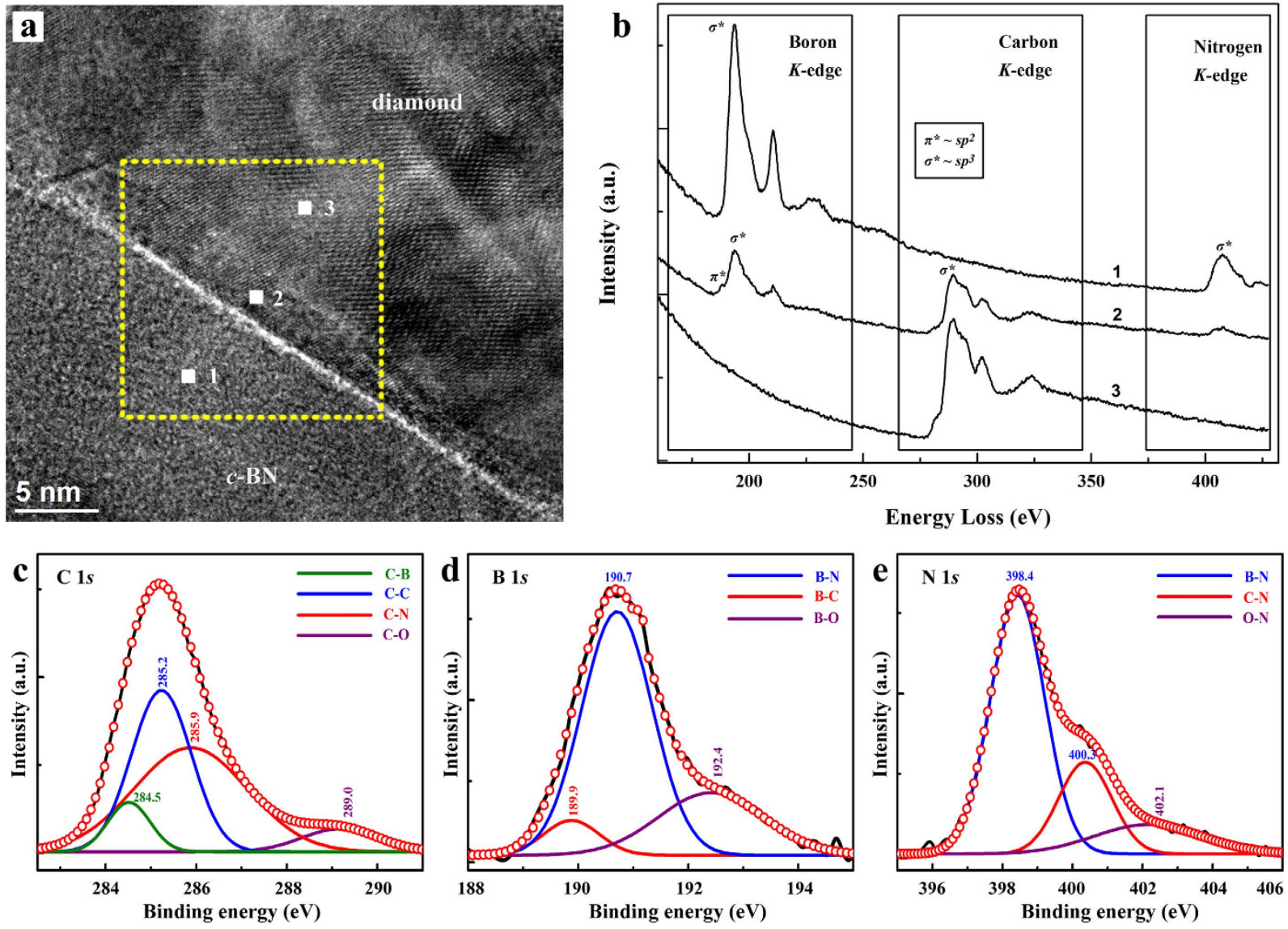

Figure 4. Evidence for $s p^{3}$-hybridized $C-B$ and $C-N$ in nanocomposite $C_{2}-B N$. (a) HRTEM image of $C_{2}-B N$ (b) EELS taken from $\mathrm{C}_{2}$-BN along the suture between diamond and $c \mathrm{BN}$ domains. EELS data were collected with a beam approximately $1 \times 1 \mathrm{~nm}$ in size. Symbols $\pi^{*}$ and $\sigma^{*}$ correspond to $s p^{2}$ and $s p^{3}$ bonding, respectively. (c-e) XPS spectra of B, C, and N $1 s$ core levels, respectively. The spectra (red circles) are deconvolved (colored curves) by Gaussian fitting.

Vickers hardness measurements were conducted on the $\mathrm{C}_{x}$ - $\mathrm{BN}$ nanocomposites using a standard square-pyramidal diamond indenter. We imaged and compared the indented surfaces using an optical microscope, SEM, and well-calibrated 3D optical microscope to determine the $H_{V}$ value. Figure 5a shows the hardness-load curve of $\mathrm{C}_{2}-\mathrm{BN}$. The asymptotic region is reached at loads above $4.9 \mathrm{~N}$ and shows an ultrahard value of $82(3) \mathrm{GPa}$ at $19.6 \mathrm{~N}$. In a second $\mathrm{C}_{2}-\mathrm{BN}$ sample, the indentation at $19.6 \mathrm{~N}$ load corresponded to $H_{V}=85(2) \mathrm{GPa}$, confirming the ultrahard value of our nanocomposite $\mathrm{C}_{2}-\mathrm{BN}$. For other compositions of $\mathrm{C}_{x}-\mathrm{BN}$ as well as $c \mathrm{BN}$ and sintered diamond, we studied indentations at $19.6 \mathrm{~N}$ load and found a peak hardness for the composition $\mathrm{C}_{2}$ - $\mathrm{BN}$ (Fig. $5 \mathrm{~b}$ ). $H_{\mathrm{V}}$ of the sintered diamond sample is lower than sintered $c \mathrm{BN}$ because of the presence of a graphitic phase on the diamond surface (Fig. S8).

The compressibility of $\mathrm{C}_{2}$ - $\mathrm{BN}$ was studied under quasi-hydrostatic pressures up to $40 \mathrm{GPa}$ at $300 \mathrm{~K}$ in a diamond-anvil cell using synchrotron X-ray diffraction at Sector 16 (HPCAT) of the Advanced Photon Source (APS). Figure $\mathrm{S} 10$ shows the compression data of diamond and $c \mathrm{BN}$ domains in the bulk $\mathrm{C}_{2}-\mathrm{BN}$ sample, together with the previously reported equations of state of single-crystal diamond ${ }^{36}$ and ultrahard nanopolycrystalline (NP) $c \mathrm{BN}^{17}$. The $P-V$ data (Table S2) were fitted to a third-order Vinet equation of state, finding for diamond $V_{0}=45.33( \pm 0.01) \AA^{3}$ and $K_{\mathrm{T} 0}=436.4( \pm 2.3) \mathrm{GPa}$ when $K_{0}{ }^{\prime}=3.0$ is fixed to the value from a previous study ${ }^{36}$ to allow for better comparison of $K_{\mathrm{T} 0}$. Our value of $K_{\mathrm{T} 0}$ is close to the adiabatic bulk modulus derived from recent ultrasonic measurements, $K_{\mathrm{T} 0}=441.8( \pm 0.8)$ for single-crystal diamond and $K_{\mathrm{T} 0}=442.5( \pm 0.5) \mathrm{GPa}$ for NP-diamond ${ }^{37}$. For the $c \mathrm{BN}$ domains, we obtained $V_{0}=47.30( \pm 0.01) \AA^{3}$ and $K_{\mathrm{T} 0}=398.6( \pm 2.5) \mathrm{GPa}$ when $K_{0}{ }^{\prime}=2.3$ is fixed to the value of a previous study ${ }^{17,38}$. When $K_{0}$ ' is allowed to refine, we obtain $V_{0}=47.33( \pm 0.01)$ $\AA^{3}, K_{\mathrm{T} 0}=377.4( \pm 7.1) \mathrm{GPa}$, and $K_{0}{ }^{\prime}=3.6( \pm 0.4)$ (Fig. S10). Using $K_{\mathrm{T} 0}=398.6( \pm 2.5) \mathrm{GPa}$ for the $c \mathrm{BN}$ domains, we obtain a theoretical nanopolycrystalline average $K_{\mathrm{T} 0}$ value of the $\mathrm{C}_{2}$ - $\mathrm{BN}$ composite of $417.5( \pm 2.4) \mathrm{GPa}$.

We also determined the thermal stability (in air) of the $\mathrm{C}_{x}$ - $\mathrm{BN}$ samples by thermoanalytical analysis (TG/DTG) from $400 \mathrm{~K}$ to $1620 \mathrm{~K}$ (Fig. $5 \mathrm{c}$ ). The synthetic $\mathrm{C}_{2}$ - $\mathrm{BN}$ sample shows remarkably higher stability than either single-crystal boron-doped diamond $(\sim 1000 \mathrm{ppm})$ with the onset temperature of oxidation in air, $\mathrm{T}_{\mathrm{OX}} \sim 1027 \mathrm{~K}$, or nanopolycrystalline diamond $\left(\mathrm{T}_{\mathrm{OX}} \sim 950 \mathrm{~K}\right)^{17}$. The synthetic nanocomposite of $\mathrm{C}_{2}-\mathrm{BN}$ remains stable up to $1183 \mathrm{~K}$. Moreover, the oxidation rate for $\mathrm{C}_{2}$ - $\mathrm{BN}$ composite decreases substantially between $1183 \mathrm{~K}$ and $1425 \mathrm{~K}$. 

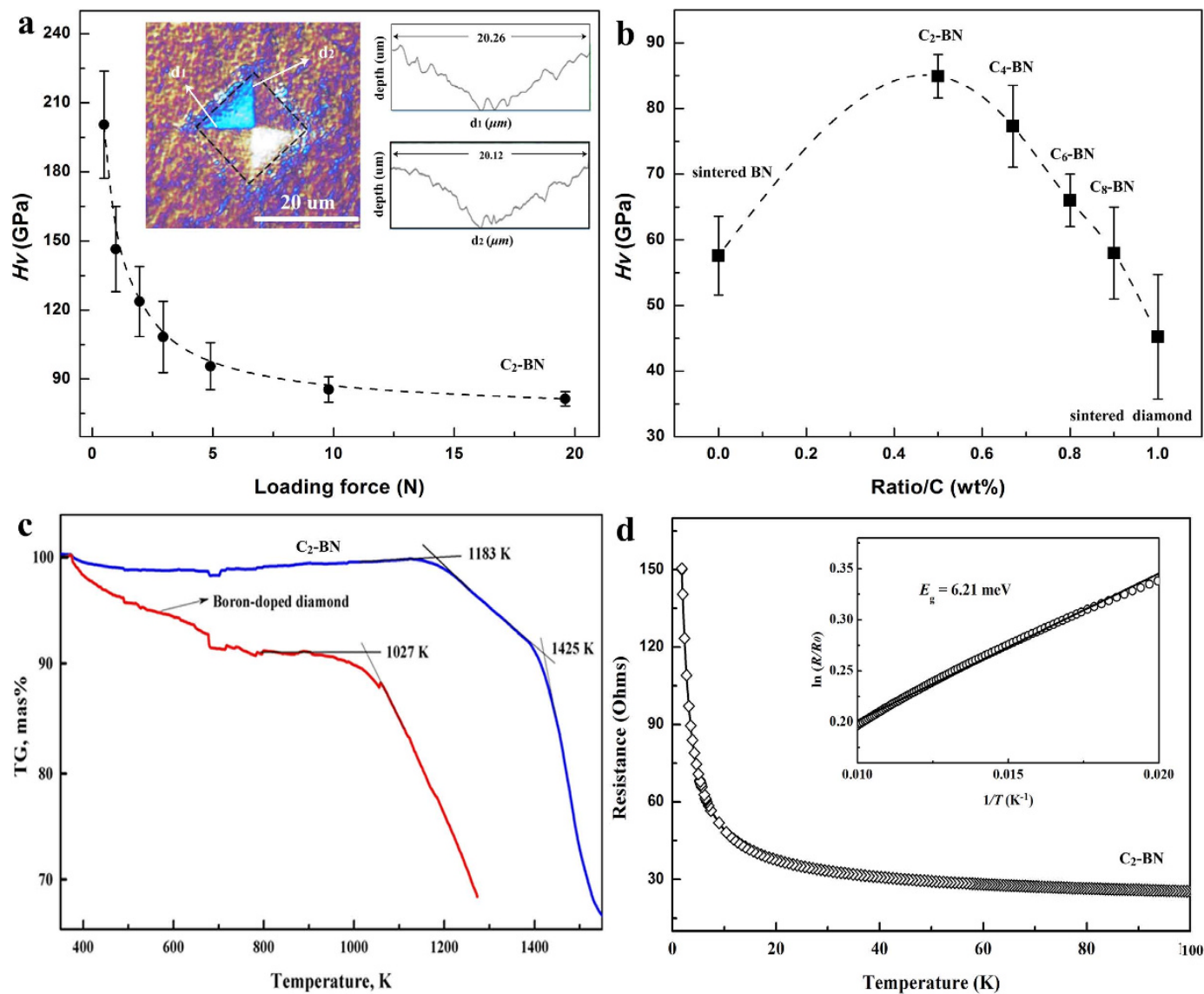

Figure 5. Mechanical and electrical properties of $\mathrm{C}_{2}$ - $\mathrm{BN}$ nanocomposite. (a) $\mathrm{H}_{v}$ of $\mathrm{C}_{2}$ - $\mathrm{BN}$ as a function of applied load. Left inset: Optical micrograph of an indentation in $\mathrm{C}_{2}-\mathrm{BN}$ produced by a load of $19.6 \mathrm{~N}$. Right inset images in (a) show profiles across $\mathrm{d}_{1}$ and $\mathrm{d}_{2}$ measured using a $3 \mathrm{D}$ microscope. (b) $H_{v}$ as a function of composition for $\mathrm{C}_{x}$ - $\mathrm{BN}$ materials. For comparison, we measured the Vickers hardness of $\mathrm{C}_{x}$ - $\mathrm{BN}$ with higher diamond: $c \mathrm{BN}$ ratios at only the highest load of $19.6 \mathrm{~N}$. The measured indentation hardness of $\mathrm{C}_{x}-\mathrm{BN}$ ranged from $40 \mathrm{GPa}$ to $85 \mathrm{GPa}$. (c), Thermogravimetric data (in air) for $\mathrm{C}_{2}-\mathrm{BN}$ (the onset temperature of oxidation $T_{o x}$ is $1183 \mathrm{~K}$ ) and boron-doped diamond single crystals $\left(T_{o x} \sim 1027 \mathrm{~K}\right)$. (d) A resistance-versus-temperature curve for $\mathrm{C}_{2}$-BN measuring $2 \times 2 \mathrm{~mm}$ and $1 \mathrm{~mm}$ thick. The inset in $(\mathbf{d})$ shows $\ln (R)$ as a function of $T^{-1}$ in the temperature range from 50 to $100 \mathrm{~K}$. The linear fit (solid line) shows that the data are well described by $R(T) \propto \exp \left(E_{\mathrm{g}} / k_{\mathrm{B}} T\right)$, where $E_{\mathrm{g}}$ is the activation energy and $k_{\mathrm{B}}$ is Boltzmann's constant.

To investigate the electrical properties of our synthetic $\mathrm{C}_{x}$-BN nanocomposites, Hall measurements were performed with four electrodes at room temperatures (Table 1). The sintered diamond (sample $\mathrm{S} 6$ ) and $\mathrm{C}_{x}-\mathrm{BN}$ materials with high carbon concentration (sample S5) show good $n$-type conductivity with a low resistivity that can be due to the graphitization under HPHT treatment. Both $\mathrm{C}_{2}-\mathrm{BN}$ and $\mathrm{C}_{4}$ - $\mathrm{BN}$ nanocomposites synthesized at $2273 \mathrm{~K}$ and 7.5 GPa exhibit $p$-type semiconductivity. Resistivity of the $p$-type $\mathrm{C}_{x}$ - $\mathrm{BN}$ is observed to decrease and the carrier concentration increases with increasing synthetic temperature condition up to $2273 \mathrm{~K}$ (sample S9 and S10). The p-type $\mathrm{C}_{x}$-BN synthesized at $2273 \mathrm{~K}$ (sample S2-4) shows low electrical resistivity, and the electron and hole mobility is in a wide range of $2.7-365 \mathrm{~cm}^{2} \mathrm{~V}^{-1} \mathrm{~s}^{-1}$. The carrier concentration of the $\mathrm{C}_{2}-\mathrm{BN}$ composite can reach $1.4387 \times 10^{19} \mathrm{~cm}^{-3}$ at $300 \mathrm{~K}$. This value is comparable with that of $\mathrm{B}$-doped diamond ${ }^{39}$. These results suggest that we can control the electrical properties of our $\mathrm{C}_{x}-\mathrm{BN}$ materials from insulator to highly conducting by adjusting synthetic $P$-T or tuning the ratio between the $\mathrm{C}$ and $\mathrm{BN}$ with high flexibility and applications in electronics.

Temperature-dependent electrical measurements on our $\mathrm{C}_{2}$ - $\mathrm{BN}$ nanocomposite (Fig. $5 \mathrm{~d}$ ) show a significant increase in resistance by more than 7 -fold on cooling from room temperature $(\rho=21 \Omega)$ to $1.8 \mathrm{~K}$, a typical semiconducting behavior. The value of the activation energy is calculated on the basis of a linear Arrhenius plot of the logarithm of the resistance $\ln (R)$ versus the inverse temperature $T^{-1}$ in the temperature range between from $100 \mathrm{~K}$ and $50 \mathrm{~K}$ (See Fig. 5d, inset). The calculated activation energy is $6.21 \mathrm{meV}$ and is similar to hybridized BN-C graphene ${ }^{30}$. Since both pure diamond and $c \mathrm{BN}$ are good insulators, the $p$-type semiconductivity of the $\mathrm{C}_{x}-\mathrm{BN}$ composite must derive from the $s p^{3}$-hybridized C-B and some B-B bonds within the sutures of diamond and $c \mathrm{BN}$ domains ${ }^{30,40}$.

This study introduces a new strategy and direction in the search for novel conductive ultrahard materials. Nanocomposite $\mathrm{C}_{x}$-BN materials will enable the design of particular physical properties in diamond-based structures. Previously, B-doping has been the most effective method used to control the electrical properties of 
diamond. However, it is difficult to synthesize high-quality diamond crystals with heavy B-doping because boron is typically heterogeneously distributed within the crystal and it is difficult to avoid graphitic defects ${ }^{41,42}$. The current synthesis and characterization of $p$-type bulk nanopolycrystalline $\mathrm{C}_{x}$ - $\mathrm{BN}$ with low activation energy suggests that stable and uniform diamond-based semiconductors can be formed in large quantities and in a reproducible way. In addition, the well-sintered nanopolycrystalline bulk pieces possess no cleavage, which will allow $\mathrm{C}_{x}$ - $\mathrm{BN}$ composite materials to be fabricated into arbitrary shapes for industrial applications such as machine parts. Combining the high thermal conductivity and radiation resistance of diamond with the toughness of $c \mathrm{BN}$ at high temperatures, the ultrahard $\mathrm{C}_{x}$ - $\mathrm{BN}$ bulk nanocomposites have potential applications in electronics under extreme thermal and pressure conditions.

In summary, we synthesized $\mathrm{C}_{x}$ - $\mathrm{BN}$ composites with dimensions up to $10 \mathrm{~mm} \times 5 \mathrm{~mm}$ at $7.5 \mathrm{GPa}$ and $2273 \mathrm{~K}$. The composite of nanotwinned diamond and $c \mathrm{BN}$ in a 2:1 ratio $\left(\mathrm{C}_{2}-\mathrm{BN}\right)$ shows ultrahard properties by Vickers indentation tests, low compressibility, high thermal stability, and $p$-type semiconductivity - a combination of features that have not previously been found together in pure diamond-like B-C-N materials. Subsequent annealing at $15-18 \mathrm{GPa}$ and $2100 \mathrm{~K}$ improves its transparency. The nanotwinned domains of diamond and $c \mathrm{BN}$ are stitched by $s p^{3}$-hybridized C-B and C-N bonds with dislocations near the grain boundaries to accommodate the rigid lattice mismatch of diamond and $c \mathrm{BN}$, thus combining the features of a variety of recently reported ultrahard materials ${ }^{1-3,18,23-24}$. The moderate synthesis $P$-T conditions and rapid annealing time ( 2 hours) to form ultrahard nanopolycrystalline $\mathrm{C}_{2} \mathrm{BN}$ composite make it a promising material for machine tooling with other practical benefits. The unique combination of properties in $\mathrm{C}_{2}$ - $\mathrm{BN}$ provides a pathway for fabrication of diamond-based electronics applicable to multifunctional devices operating in extreme environments.

\section{Methods}

Sample synthesis and characterization. HP-HT synthesis experiments were carried out using a Chinatype cubic high-pressure apparatus $($ SPD $-6 \times 1200)$ at the State Key Laboratory of Superhard Materials, Jilin University. High-purity mixtures were prepared of nanodiamond $(50 \mathrm{~nm})$ and $c \mathrm{BN}(250 \mathrm{~nm})$ with varying ratios $(x)$ of diamond to $c \mathrm{BN}$ (i.e. $\mathrm{C}_{x}-\mathrm{BN}$ ), including $\mathrm{BN}, \mathrm{C}_{2}-\mathrm{BN}, \mathrm{C}_{4}-\mathrm{BN}, \mathrm{C}_{6}-\mathrm{BN}, \mathrm{C}_{8}-\mathrm{BN}, \mathrm{C}_{10}-\mathrm{BN}, \mathrm{C}_{12}-\mathrm{BN}$ and $\mathrm{C}$. The starting materials were prepared by mechanically mixing for five hours at ambient conditions and treated by hot sulfuric acid/diluted hydrochloric acid to remove impurities introduced during the milling progress. Synthesis temperatures were measured using a Pt-30\% Rh/Pt-6\%Rh thermocouple junction placed within $0.5 \mathrm{~mm}$ of the sample. Pressure was pre-calibrated at high temperatures by the graphite-diamond transition with different catalysts. Samples were first subjected to pressures of $7.5 \mathrm{GPa}$, heated to temperatures of $1500-2273 \mathrm{~K}$ with holding times of 2 hours before rapidly cooling to room temperature in 2 minutes. The $\mathrm{C}_{x}$-BN cylinders $(10-\mathrm{mm}$ diameter $\times 5$-mm height) are black in color. One sample of $\mathrm{C}_{2}-\mathrm{BN}$ was re-annealed at $15-18 \mathrm{GPa}$ and $2100 \mathrm{~K}$ for 2 hours using the 1000-ton multi-anvil press at GSECARS (Sector 13) of the APS, Argonne National Laboratory (ANL), producing a transparent and colorless run product (Fig. S3). Run products were initially studied using an optical microscope, SEM, a powder XRD diffractometer, and Raman spectroscopy. Then we employed HRTEM, EELS, IXS, and XPS measurements on the produced $\mathrm{C}_{x}$ - BN composites to determine their chemical compositions and crystal structures.

Hardness and thermal stability measurement. Vickers Hardness measurements were performed in the Optical Microscopy \& Metallography (OMM) Facility at Northwestern University. A microhardness tester (KB $5 \mathrm{BVZ}$ ) was used to measure $H_{V}$ with a diamond Vickers indenter. $H_{V}$ was determined from $H_{V}=1,854.4 F / d^{2}$, where $F$ (in Newtons) is the applied load and $d$ (in $\mu \mathrm{m}$ ) is the arithmetic mean of the two diagonals $\left(d_{1}\right.$ and $\left.d_{2}\right)$ of the Vickers indentation (Fig. 5a). For $\mathrm{C}_{2}$-BN, the average of at least seven hardness data points for each load value was used to determine the $H_{\mathrm{V}}$ from the asymptotic intercept. To study the effect of cracking around the projected area on the inferred indentation dimensions, we used a combination of optical microscopy, SEM, and a high-resolution 3D microscope (Bruker, ContourGT Optical Profiler) to analyze the indented surface. The dynamic TG/DTG studies were performed in air using the NETZSCH STA 449 C thermoanalyser operating at a heating rate of $10 \mathrm{~K} \mathrm{~min}^{-1}$ in the temperature range from 200 to $1650 \mathrm{~K}$. These bulk samples were crushed into powders of micron sizes before the thermoanalytical studies.

Compressibility. The compressibility measurement was carried out in diamond-anvil cell using neon as the pressure medium. High-pressure X-ray diffraction patterns were collected up to $40 \mathrm{GPa}$, with exposure times of 5-10 min, at room temperature at beamline 16BM-D (HPCAT) of the APS. The beam size was $\sim 5 \times 10 \mu \mathrm{m}$ at FWHM. Pressure was measured using the ruby fluorescence method ${ }^{43}$. A fragment of $\mathrm{C}_{2}-\mathrm{BN}(50 \mu \mathrm{m}$ diameter, $8-10 \mu \mathrm{m}$ thick) was placed into the $160-\mu \mathrm{m}$ diameter hole of a rhenium gasket, pre-indented to $25 \mu \mathrm{m}$ thickness.

Electrical measurement. The van der Pauw method was used for electrical transport measurements, in which four electrodes were used in the resistivity measurements. The electrical characteristics were measured with a transport properties measuring system (East Changing ET 9000 Series). The resistivity measurements were carried out at room temperature $(300 \mathrm{~K})$ and normal humidity level $(40 \% \mathrm{RH})$. The temperature dependence of the resistance was measured using a standard four-probe method (PPMS, Quantum Design).

\section{References}

1. Irifune, T., Kurio, A., Sakamoto, S., Inoue, T. \& Sumiya, H. Materials: Ultrahard polycrystalline diamond from graphite. Nature 421, 599-600 (2003)

2. Tian, Y. et al. Ultrahard nanotwinned cubic boron nitride. Nature 493, 385-388 (2013).

3. Huang, Q. et al. Nanotwinned diamond with unprecedented hardness and stability. Nature 510, 250-253 (2014).

4. Gou, H. et al. Discovery of a superhard iron tetraboride superconductor. Phys. Rev. Lett. 111, 157002 (2013).

5. Wentorf, R., DeVries, R. C. \& Bundy, F. Sintered superhard materials. Science 208, 873-880 (1980). 
6. Ding, X., Liew, W. \& Liu, X. Evaluation of machining performance of MMC with PCBN and PCD tools. Wear 259, 1225-1234 (2005).

7. Knittle, E., Kaner, R., Jeanloz, R. \& Cohen, M. High-pressure synthesis, characterization, and equation of state of cubic C-BN solid solutions. Phys. Rev. B 51, 12149 (1995).

8. Leger, J. et al. Discovery of hardest known oxide. Nature 383, 401-401 (1996).

9. Liu, A. Y. \& Cohen, M. L. Prediction of new low compressibility solids. Science 245, 841-842 (1989).

10. Zhao, Y. et al. Superhard B-C-N materials synthesized in nanostructured bulks. J. Mater. Res. 17, 3139-3145 (2002).

11. Kaner, R. B., Gilman, J. J. \& Tolbert, S. H. Designing superhard materials. Science 308, 1268-1269 (2005).

12. Steeds, J. et al. Use of novel methods for the investigation of the boron distribution in CVD diamond. Acta Mater. 47, 4025-4030 (1999).

13. Solozhenko, V. L., Andrault, D., Fiquet, G., Mezouar, M. \& Rubie, D. C. Synthesis of superhard cubic BC 2 N. Appl. Phys. Lett. 78 (2001).

14. Zhang, M. et al. Superhard $\mathrm{BC}_{3}$ in cubic diamond structure. Phys. Rev. Lett. 114, 015502 (2015).

15. Solozhenko, V. L., Kurakevych, O. O., Andrault, D., Le Godec, Y. \& Mezouar, M. Ultimate metastable solubility of boron in diamond: synthesis of superhard diamondlike $\mathrm{BC}_{5}$. Phys. Rev. Lett. 102, 015506 (2009).

16. Li, Q. et al. Superhard and superconducting structures of $\mathrm{BC}_{5}$. J. Appl. Phys. 108 (2010).

17. Solozhenko, V. L., Kurakevych, O. O. \& Le Godec, Y. Creation of nanostuctures by extreme conditions: high-pressure synthesis of ultrahard nanocrystalline cubic boron nitride. Adv. Mater. 24, 1540-1544 (2012).

18. Li, B., Sun, H. \& Chen, C. Large indentation strain-stiffening in nanotwinned cubic boron nitride. Nat. Commun. 5 (2014).

19. Mishima, O., Tanaka, J., Yamaoka, S. \& Fukunaga, O. High-temperature cubic boron nitride $p n$ junction diode made at high pressure. Science 238, 181-183 (1987).

20. Taniguchi, T. \& Yamaoka, S. In MRS Proceedings. 379 (Cambridge Univ Press).

21. Zhang, W. et al. Epitaxy on diamond by chemical vapor deposition: a route to high-quality cubic boron nitride for electronic applications. Adv. Mater. 16, 1405-1408 (2004).

22. Zhang, X. et al. Epitaxy of cubic boron nitride on (001)-oriented diamond. Nat. Mater. 2, 312-315 (2003).

23. Wang, P. et al. Diamond-cBN alloy: A universal cutting material. Appl. Phys. Lett. 107, 101901 (2015).

24. Chen, C. et al. Misfit accommodation mechanism at the heterointerface between diamond and cubic boron nitride. Nat. Commun. 6 (2015).

25. Liu, J., Huang, J., Zhou, H. \& Antonietti, M. Uniform graphitic carbon nitride nanorod for efficient photocatalytic hydrogen evolution and sustained photoenzymatic catalysis. ACS Appl. Mat. Interfaces 6, 8434-8440 (2014).

26. Ahmed, M. H., Byrne, J. A., McLaughlin, J., Elhissi, A. \& Ahmed, W. Comparison between FTIR and XPS characterization of amino acid glycine adsorption onto diamond-like carbon (DLC) and silicon doped DLC. Appl. Surf. Sci. 273, 507-514 (2013).

27. Belton, D. N., Harris, S. J., Schmieg, S. J., Weiner, A. M. \& Perry, T. A. Insitu characterization of diamond nucleation and growth. Appl. Phys. Lett. 54, 416-417 (1989).

28. Hao, X. et al. Synthesis of cubic boron nitride at low-temperature and low-pressure conditions. Chem. Mater. 13, 2457-2459 (2001).

29. Liu, X. et al. Synthesis and characterization of new "BCN" diamond under high pressure and high temperature conditions. Cryst. Growth Des. 11, 1006-1014 (2011).

30. Ci, L. et al. Atomic layers of hybridized boron nitride and graphene domains. Nat. Mater. 9, 430-435 (2010).

31. Merel, P., Tabbal, M., Chaker, M., Moisa, S. \& Margot, J. Direct evaluation of the $s p^{3}$ content in diamond-like-carbon films by XPS. Appl. Surf. Sci. 136, 105-110 (1998).

32. Zhao, G. et al. Sulfonated graphene for persistent aromatic pollutant management. Adv. Mater. 23, 3959-3963 (2011).

33. Lazare, S., Hoh, P. D., Baker, J. M. \& Srinivasan, R. Controlled modification of organic polymer surfaces by continuous wave farultraviolet $(185 \mathrm{~nm})$ and pulsed laser $(193 \mathrm{~nm})$ radiation: XPS studies. J. Am. Chem. Soc. 106, 4288-4290 (1984).

34. Paul, R., Voevodin, A. A., Zemlyanov, D., Roy, A. K. \& Fisher, T. S. Microwave-assisted surface synthesis of a boron-carbon-nitrogen foam and its desorption enthalpy. Adv. Funct. Mater. 22, 3682-3690 (2012).

35. Liu, G., Yin, L. C., Niu, P., Jiao, W. \& Cheng, H. M. Visible-light-responsive $\beta$-rhombohedral boron photocatalysts. Angew. Chem. 125, 6362-6365 (2013).

36. Occelli, F., Loubeyre, P. \& LeToullec, R. Properties of diamond under hydrostatic pressures up to 140 GPa. Nat. Mater. 2, 151-154 (2003).

37. Chang, Y.-Y., Jacobsen, S. D., Kimura, M., Irifune, T. \& Ohno, I. Elastic properties of transparent nano-polycrystalline diamond measured by GHz-ultrasonic interferometry and resonant sphere methods. Phys. Earth Planet. Inter. 228, 47-55 (2014).

38. Datchi, F., Dewaele, A., Le Godec, Y. \& Loubeyre, P. Equation of state of cubic boron nitride at high pressures and temperatures. Phys. Rev. B 75, 214104 (2007).

39. Zhang, R., Lee, S. T. \& Lam, Y. Characterization of heavily boron-doped diamond films. Diamond Relat. Mater. 5, 1288-1294 (1996).

40. Watanabe, M., Itoh, S., Sasaki, T. \& Mizushima, K. Visible-light-emitting layered $\mathrm{BC}_{2} \mathrm{~N}$ semiconductor. Phys. Rev. Lett. 77, 187 (1996).

41. Wurzinger, P., Pongratz, P., Hartmann, P., Haubner, R. \& Lux, B. Investigation of the boron incorporation in polycrystalline CVD diamond films by TEM, EELS and Raman spectroscopy. Diamond Relat. Mater. 6, 763-768 (1997).

42. Dubrovinskaia, N. et al. Superhard nanocomposite of dense polymorphs of boron nitride: Noncarbon material has reached diamond hardness. Appl. Phys. Lett. 90, 101912 (2007).

43. Mao, H., Xu, J.-A. \& Bell, P. Calibration of the ruby pressure gauge to $800 \mathrm{kbar}$ under quasi-hydrostatic conditions. J. Geophys. Res. Sol. Ea. 91, 4673-4676 (1986).

\section{Acknowledgements}

This work was supported by NSF grants DMR-1508577 to SDJ and CRB, EAR-1361276 to YW, and DMR1411344 to JG. SDJ also acknowledges support from the David and Lucile Packard Foundation, the Alexander von Humboldt Foundation, and the Carnegie/DOE Alliance Center (CDAC). Synthesis experiments were performed at State Key Lab of Superhard Materials, Jilin University. Sample characterization was conducted in the EPIC facility (NUANCE Center-Northwestern University), supported by the MRSEC program (NSF DMR1121262) at the Materials Research Center, the International Institute for Nanotechnology (IIN), and the State of Illinois. Annealing experiments carried out at GESCARS (Sector 13 of the APS) were supported by the NSF (EAR-1128799) and DOE (DE-FG02-94ER14466). The FIB at Bayerisches Geoinstitut, University of Bayreuth, Germany, was financed by DFG grant No. INST 91/315-1 FUGG. The Optical Microscopy \& Metallography Facility at Northwestern University receives support from the MRSEC Program (NSF DMR-1121262) of the Materials Research Center. Portions of this work were performed at HPCAT (Sector 16 of the APS). HPCAT operations are supported by DOE-NNSA under Award No. DE-NA0001974 and DOE-BES under Award No. DE-FG02-99ER45775, with partial instrumentation funding by NSF. We thank Changyong Park for assistance with the XRD measurements at HPCAT. Use of the APS was supported by the DOE-BES under Contract No. DE-AC02-06CH11357. 


\section{Author Contributions}

X.L. designed the study. X.L., X.C., S.D.J., Y.W. and C.R.B. wrote the manuscript. X.L., X.C., H.-A.M. and X.J. synthesized the samples and performed the thermoanalytical measurements. J.G. performed the electrical measurements. X.L., T.Y. and Y.W. conducted HPHT annealing experiments. X.L. performed the high-pressure X-ray diffraction experiments. S.D.J. and S.P. conducted FIB preparation, X.L. and J.W. conducted SEM and HRTEM measurements. All authors contributed to data analysis, interpretation, and revision of the manuscript.

\section{Additional Information}

Supplementary information accompanies this paper at http://www.nature.com/srep

Competing financial interests: The authors declare no competing financial interests.

How to cite this article: Liu, X. et al. Ultrahard stitching of nanotwinned diamond and cubic boron nitride in $\mathrm{C}_{2}$-BN composite. Sci. Rep. 6, 30518; doi: 10.1038/srep30518 (2016).

(c) (i) This work is licensed under a Creative Commons Attribution 4.0 International License. The images or other third party material in this article are included in the article's Creative Commons license, unless indicated otherwise in the credit line; if the material is not included under the Creative Commons license, users will need to obtain permission from the license holder to reproduce the material. To view a copy of this license, visit http://creativecommons.org/licenses/by/4.0/

(C) The Author(s) 2016 